\title{
Cancer screening rate in people with diabetes in the Korean population: results from the Korea National Health and Nutrition Examination Survey 2007-2009
}

\author{
Kumban Walter Chuck ${ }^{1}$, Minji Hwang ${ }^{2}$, Kui Son Choi ${ }^{1,3}$, Mina Suh³ ${ }^{3}$ Jae Kwan Jun ${ }^{1,3}$, \\ Boyoung Park ${ }^{1,3}$ \\ 'Department of Cancer Control and Population Health, National Cancer Center Graduate School of Cancer Science and Policy, Goyang, Korea; \\ ${ }^{2}$ Research Center, National Cancer Center, Goyang, Korea; ${ }^{3}$ National Cancer Control Institute, National Cancer Center, Goyang, Korea
}

\begin{abstract}
OBJECTIVES: To investigate the screening rates for gastric, breast, and cervical cancer in people with diabetes compared with people without diabetes.

METHODS: Data from the Korea National Health and Nutrition Examination Survey (2007-2009) were used. Cancer-free men who were 40 years old and over and cancer-free women who were 30 years old and over were included. The lifetime screening rate and regular screening rate were compared in people with and without diabetes.
\end{abstract}

RESULTS: Fewer people with diabetes than people without diabetes had ever received cancer screening $(53.5$ vs. $59.5 \%$, p $<0.001$ for gastric cancer; 60.5 vs. $71.5 \%$, p $<0.001$ for breast cancer; and 49.1 vs. $59.6 \%, \mathrm{p}<0.001$ for cervical cancer). Fewer people with diabetes than people without diabetes received the recommended screenings for gastric cancer ( 38.9 vs. $42.9 \%$, p $<0.001)$, breast cancer ( 38.8 vs. $44.6 \%, \mathrm{p}<0.001$ ), and cervical cancer ( 35.1 vs. $51.2 \%, \mathrm{p}<0.001$ ). In subgroup analyses according to socioeconomic factors, the lifetime and recommended screening rates were lower in the diabetic population in most socioeconomic subgroups. In the multivariate analysis adjusted for socioeconomic factors, people with diabetes showed lower lifetime screening rates for gastric and cervical cancer (odds ratio [OR], 0.8; 95\% confidence interval [CI], 0.7 to 0.9 and OR, 0.7; 95\% CI, 0.6 to 0.9 ), and lower regular screening rates for breast and cervical cancer (OR, 0.7; 95\% CI, 0.6 to 0.9 and $\mathrm{OR}, 0.7 ; 95 \% \mathrm{CI}, 0.5$ to 0.9 ).

CONCLUSIONS: The cancer screening rate in people with diabetes was lower than in people without diabetes. Considering the higher cancer risk in people with diabetes, efforts to increase the screening rate in this high-risk population should be implemented.

KEY WORDS: Early detection of cancer, Diabetes mellitus, Nationwide cross-sectional study, Korea National Health and Nutrition Examination Survey

\section{Correspondence: Boyoung Park}

Department of Cancer Control and Population Health, National Cancer Center Graduate School of Cancer Science and Policy, 323 Ilsan-ro, Ilsandong-gu, Goyang 10408, Korea

E-mail: hayejine@ncc.re.kr

Received: Jan 3, 2017 / Accepted: Aug 10, 2017 / Published: Aug 10, 2017

This article is available from: http://e-epih.org/

(C) This is an open-access article distributed under the terms of the Creative Commons Attribution License (http://creativecommons.org/licenses/by/4.0/), which permits unrestricted use, distribution, and reproduction in any medium, provided the original work is properly cited.

(C) 2017, Korean Society of Epidemiology

\section{INTRODUCTION}

Cancer is one of the major public health burdens in both developed and developing countries; it leads to increased mortality, and its incidence is increasing [1]. The global burden of diabetes has nearly doubled since 1980 , from 4.7 to $8.5 \%$ in the adult population. This reflects an increase in associated risk factors such as obesity [2]. Diabetes and cancer are both chronic diseases that cause a health burden worldwide, and some epidemiologic studies have suggested that individuals with diabetes have a significantly higher risk for cancer, including gastric, breast, and cervical cancers [3-6]. Increasing the screening rates for these cancers in peo- 
ple with diabetes will go a long way to reduce the burden related to the cancer-related sequelae of diabetes [7]. Thus, several studies have examined the cancer screening rate in people with diabetes, but have shown some discrepancies in the cancer screening rates of people with diabetes compared to people without diabetes [8-10].

In Korea, cancer has been one of the leading causes of death since 1983 [11], and is also expected to become more common due to aging and westernized lifestyles [12]. In 1999, the National Cancer Screening Program (NCSP) was implemented by the Korean government as an organized cancer screening program, and opportunistic screenings are also provided depending on individuals' needs [13]. Diabetes and its complications have also emerged as a major cause of morbidity and mortality. The prevalence of diabetes has increased 6-7-fold in the past 40 years [14]; although diabetes-related deaths have decreased since 2002, it still remains the fifth most common cause of death in Korea [15].

To the best of the authors' knowledge, few studies in Korea have been conducted to assess whether people with diabetes receive less, more, or equal cancer screening in comparison to those without diabetes. Therefore, this study aimed to investigate the screening rates for gastric, breast, and cervical cancer, which are included in the NCSP [13], in people with diabetes in comparison with people without diabetes.

\section{MATERIALS AND METHODS}

The primary source of data for this study was the Korea National Health and Nutrition Examination Survey (KNHANES) from 2007 to 2009. This is a nationwide survey that was put in place in 1998, and was initially conducted on a triennial basis. Since 2007, the survey has been conducted annually by the Korea Centers for Disease Control and Prevention to evaluate the health and nutritional conditions of the Korean population. The measurements in the KNHANES include direct physical examinations, clinical laboratory examinations, and personal interviews. The diabetic population was defined as including (1) people who had been diagnosed with diabetes by a physician and had received treatment for diabetes with insulin or medication, and (2) those with a fasting glucose level $\geq 126 \mathrm{mg} / \mathrm{dL}$. The non-diabetic population included people who did not meet these criteria: that is, those who had never been diagnosed with diabetes by a physician, those who had never received treatment for diabetes with insulin or medication, and those with a fasting glucose level $<126 \mathrm{mg} / \mathrm{dL}$.

In Korea, an organized cancer screening program is available for men and women in the general population 40 years of age and above, men and women 50 years of age and above, women 40 years of age and above, and women 30 years of age and above for gastric, colorectal, breast, and cervical cancer, respectively, and participants in each age category were included in the analysis of each type of cancer screening. For colorectal cancer, the option in the questionnaire that was used to estimate the most recent screening was different (within 2 years) from the period recommended by the NCSP (1-year interval), so we excluded the colorectal cancer screening rate from the analysis.

Information about cancer screening for these 4 cancers was collected by questionnaire from study participants, as well as sociodemographic characteristics. Income was analyzed based on monthly household income as follows: lowest $(<1.0$ million Korean won [KRW] per month), lower (1.0-2.5 million KRW per month), higher (2.5-4.0 million KRW per month), and highest (>4.0 million KRW per month) (note, 1,000 KRW =1 US dollar). Educational level was classified as follows: elementary, middle school, high school, and college. Participants were classified by residential area based on cities and districts, which include multiple 'dong', and counties, which include multiple 'eup' and 'myeon'. In this study, we classified dong as urban areas and 'eup' and 'myeon' as rural areas. Medical insurance was divided into the National Health Insurance (NHI) program, which is compulsory by law for all residing in the territory of Korea, and the Medical Aid program put in place by the government to ensure minimum living standards for low-income households. The questions that were analyzed included "Have you ever undergone gastric, breast, or cervical cancer screening?" If yes, participants were asked "Which screening method was used, and when was the last time that you underwent screening?" The cancer screening rate for each cancer was estimated in terms of ever-screened people, including those who had received a single screening in their lifetime, and people who had regular screening according to the guidelines recommended by NCSP, which are shown in Appendix 1. For gastric, breast, and cervical cancer screening, subjects who had undergone screening within the past 2 years were considered as having been regularly screened.

The baseline characteristics of people with and without diabetes were calculated using summary statistics and percentages and compared using the chi-square test. The weighted frequencies and screening rate percentages were calculated for the 4 different cancers at 95\% confidence intervals (CIs), and we compared the screening rates between people with and without diabetes. Multivariate logistic regression was done for gastric, breast, and cervical cancer screening in diabetic and non-diabetic participants after adjusting for age, gender, income, education, residential area, and medical insurance. Stata version 12.0 (StataCorp., College Station, TX, USA) was used for all analyses.

\section{RESULTS}

This study involved a total of 13,694 participants, including 1,500 with diabetes and 12,194 without diabetes. For gastric cancer, 10,554 participants were analyzed, including 1,436 with diabetes and 9,118 without diabetes. For breast cancer screening, 6,069 women participants, including 749 with diabetes and 5,320 without diabetes, were analyzed, and for cervical cancer, 7,946 participants were included, 785 of whom had diabetes and 7,161 of whom did not.

Table 1 compares the baseline characteristics of the study participants, all of which were significantly different between people with diabetes and those without. Participants with diabetes were older, included a lower proportion of women, were less educated, 
Table 1. Socio-demographic characteristics of the study participants in the KNHANES, 2007-2009

\begin{tabular}{|c|c|c|c|}
\hline & $\begin{array}{c}\text { With } \\
\text { diabetes }\end{array}$ & $\begin{array}{l}\text { Without } \\
\text { diabetes }\end{array}$ & $p$-value \\
\hline Age (yr) & & & $<0.001$ \\
\hline $30-39$ & $79(5.2)$ & $3,157(25.9)$ & \\
\hline $40-49$ & $198(12.9)$ & $2,967(24.3)$ & \\
\hline $50-59$ & $324(21.6)$ & $2,363(19.3)$ & \\
\hline $60-69$ & $507(33.8)$ & $2,005(16.4)$ & \\
\hline $70+$ & $397(26.5)$ & $1,702(13.9)$ & \\
\hline Gender & & & $<0.001$ \\
\hline Men & $727(48.5)$ & $5,114(41.9)$ & \\
\hline Women & $773(51.5)$ & $7,080(58.1)$ & \\
\hline Income & & & $<0.001$ \\
\hline Lowest & $509(33.9)$ & 2,433 (19.9) & \\
\hline Lower & $405(27.0)$ & $2,890(23.7)$ & \\
\hline Higher & $287(19.1)$ & $3,268(26.8)$ & \\
\hline Highest & $252(16.8)$ & $3,324(27.3)$ & \\
\hline Missing & $47(3.1)$ & $279(2.3)$ & \\
\hline \multicolumn{4}{|l|}{ Education } \\
\hline Elementary school & $761(50.7)$ & $3,652(29.9)$ & \\
\hline Middle school & $228(15.2)$ & $1,503(12.3)$ & $<0.001$ \\
\hline High school & $319(21.2)$ & $3,932(32.3)$ & \\
\hline College or more & $181(12.1)$ & $3,074(25.2)$ & \\
\hline Missing & $11(0.7)$ & $33(0.3)$ & \\
\hline Residential area & & & 0.12 \\
\hline Urban & $1,051(70.1)$ & $8,777(71.9)$ & \\
\hline Rural & $449(29.9)$ & $3,417(28.1)$ & \\
\hline Health insurance & & & $<0.001$ \\
\hline $\mathrm{NHI}$ & $1,372(91.4)$ & $11,676(95.7)$ & \\
\hline MAP & $112(7.5)$ & $416(3.4)$ & \\
\hline No health insurance & $14(0.9)$ & $101(0.8)$ & \\
\hline Missing & $2(0.1)$ & $1(0.1)$ & \\
\hline \multicolumn{4}{|l|}{ Diabetes diagnosis } \\
\hline Diagnosed by a physician & $1,145(76.3)$ & & \\
\hline Never diagnosed & $355(23.7)$ & & \\
\hline \multicolumn{4}{|l|}{ Diabetes treatment } \\
\hline Ever treated & $958(63.8)$ & & \\
\hline Never treated & $542(36.1)$ & & \\
\hline
\end{tabular}

Values are presented as number (\%).

KNHANES, Korea National Health and Nutrition Examination Survey; $\mathrm{NHI}$, National Health Insurance; MAP, Medical Aid program.

had lower income levels, and were less likely to be covered through the NHI program $(\mathrm{p}<0.001)$ than people without diabetes.

Table 2 shows the gastric cancer screening rate in people with and without diabetes. The overall lifetime screening rate for gastric cancer in people with diabetes was lower (53.5\%) than in those without diabetes $(59.5 \%, \mathrm{p}<0.001)$. In a subgroup analysis by age group, gender, income, education, residential area, and type of medical insurance, a significantly lower lifetime screening rate was found in people with diabetes who were 70 years of age or older, women, in the highest income group, less educated (elementary school or less), urban residence, and covered by the NHI program than their counterparts without diabetes in the same socio-demographic groups. In participants 70 years of age or more, the lifetime screening rate was less than $50.0 \%$, irrespective of their diabetes status. The recommended gastric cancer screening rate in people with diabetes was also lower (38.9\%) than in those without diabetes $(42.9 \%, \mathrm{p}<0.001)$. Participants 70 years of age or more with diabetes had a lower recommended screening rate than the same age group without diabetes. In addition, women participants with diabetes and those who lived in urban areas with diabetes had lower recommended screening rates than their counterparts without diabetes.

Table 3 shows the breast cancer screening rate in people with and without diabetes. The overall lifetime screening rate for breast cancer in people with diabetes was significantly lower (60.5\%) than in those without diabetes $(71.5 \%, \mathrm{p}<0.001)$. In the subgroup analyses, significantly lower screening rates were found in individuals with diabetes aged 50-59, with lowest income level, less education (elementary school or less), urban residence, and coverage by the NHI program than in their non-diabetic counterparts. The overall recommended breast cancer screening rate in people with diabetes was lower $(38.8 \%)$ than in people without diabetes $(44.6 \%$, $\mathrm{p}<0.001)$. Moreover, people with diabetes who were aged 60 or more, in the lowest income group, had an educational level of elementary school or less or high school, lived in urban areas, and those who were covered by the NHI program showed significantly lower recommended screening rates than those without diabetes.

Table 4 shows the cervical cancer screening rate in people with and without diabetes. The overall lifetime screening rate for cervical cancer in participants with diabetes was significantly lower (49.1\%) than in people without diabetes $(59.6 \%, \mathrm{p}<0.001)$. In the subgroup analysis, a significantly lower lifetime screening rate was found in people with diabetes aged 40-49 and 50-59, with the lowest educational level (elementary school or less), living in either urban or rural areas, with NHI coverage, and in the lowest or highest income groups than in their counterparts without diabetes in the same socioeconomic groups. The overall recommended cervical cancer screening rate in people with diabetes was lower than in people without diabetes ( 35.1 vs. $51.2 \%, \mathrm{p}<0.001)$. In the subgroup analysis, people with diabetes aged 30-39 and 50-59, with the lowest and highest income levels, with middle-school and high-school educations, who lived in either rural or urban areas, and who were covered by NHI showed significantly lower screening rates than those without diabetes in the same socioeconomic groups.

Table 5 shows multivariate logistic regression results for gastric, breast, and cervical cancer screening in diabetic and non-diabetic participants after adjusting for age, gender, income level, education, residential area, and health insurance. People with diabetes showed significantly lower lifetime screening rates for gastric and cervical cancer (odds ratio [OR], $0.8 ; 95 \% \mathrm{CI}, 0.7$ to 0.9 and OR, $0.7 ; 95 \% \mathrm{CI}, 0.6$ to 0.9 ), and significantly lower regular screening 
Table 2. Gastric cancer screening rate in diabetic and non-diabetic participants (ever screened and recommended screening)

\begin{tabular}{|c|c|c|c|c|c|c|}
\hline & \multicolumn{3}{|c|}{ Ever screened } & \multicolumn{3}{|c|}{ Recommended screening } \\
\hline & Diabetes $(95 \% \mathrm{Cl})$ & No diabetes $(95 \% \mathrm{Cl})$ & p-value & Diabetes $(95 \% \mathrm{Cl})$ & No diabetes $(95 \% \mathrm{Cl})$ & $\mathrm{p}$-value \\
\hline Total & $53.5(50.1,59.9)$ & $59.5(58.2,60.8)$ & $<0.001$ & $38.9(35.7,42.2)$ & $42.9(41.6,44.2)$ & $<0.001$ \\
\hline \multicolumn{7}{|l|}{ Age (yr) } \\
\hline $40-49$ & $55.2(46.9,59.7)$ & $57.5(55.4,59.7)$ & 0.59 & $40.2(32.4,48.5)$ & $41.9(39.9,44.1)$ & 0.68 \\
\hline $50-59$ & $60.4(53.4,67.1)$ & $65.8(63.4,68.2)$ & 0.14 & $46.9(40.2,53.7)$ & $47.8(45.4,50.3)$ & 0.80 \\
\hline $60-69$ & $59.5(53.9,64.9)$ & $64.3(61.5,66.9)$ & 0.13 & $42.5(37.0,48.1)$ & $46.5(43.7,49.2)$ & 0.21 \\
\hline $70+$ & $33.7(28.6,39.3)$ & $45.3(42.4,48.3)$ & $<0.001$ & $21.4(17.3,26.1)$ & $30.1(27.6,32.7)$ & 0.002 \\
\hline \multicolumn{7}{|l|}{ Gender } \\
\hline Men & $55.5(50.8,60.5)$ & $58.5(56.5,60.5)$ & 0.28 & $41.6(36.9,46.4)$ & $42.6(40.7,44.6)$ & 0.69 \\
\hline Women & $50.8(46.4,55.5)$ & $60.3(58.6,61.9)$ & $<0.001$ & $35.5(31.3,39.9)$ & $43.1(41.4,44.7)$ & 0.002 \\
\hline \multicolumn{7}{|l|}{ Income } \\
\hline Lowest & $47.2(41.9,52.6)$ & $51.9(49.4,54.6)$ & 0.12 & $31.9(27.1,37.3)$ & $37.0(34.5,39.6)$ & 0.09 \\
\hline Lower & $54.8(48.3,61.3)$ & $56.6(53.9,59.3)$ & 0.63 & $39.1(32.9,45.6)$ & $39.4(36.8,42.1)$ & 0.91 \\
\hline Higher & $54.8(46.7,62.7)$ & $58.7(56.1,61.3)$ & 0.36 & $41.9(34.5,49.6)$ & $41.8(39.3,44.4)$ & 0.99 \\
\hline Highest & $59.9(51.9,67.4)$ & $68.6(66.2,71.1)$ & 0.03 & $45.6(37.8,53.5)$ & $51.6(49.1,54.2)$ & 0.16 \\
\hline \multicolumn{7}{|l|}{ Education } \\
\hline Elementary school & $48.1(43.5,52.8)$ & $54.9(52.8,56.8)$ & 0.009 & $35.1(30.7,39.7)$ & $38.8(36.8,40.8)$ & 0.15 \\
\hline Middle school & $54.7(46.1,63.0)$ & $62.6(59.5,65.7)$ & 0.08 & $40.3(32.5,48.6)$ & $44.1(40.8,47.3)$ & 0.41 \\
\hline High school & $59.4(52.2,66.3)$ & $58.1(55.6,60.5)$ & 0.72 & $43.1(36.1,50.3)$ & $41.1(38.7,43.5)$ & 0.60 \\
\hline College or more & $61.5(51.4,70.8)$ & $66.5(63.6,69.4)$ & 0.33 & $45.1(35.6,55.1)$ & $51.5(48.4,54.5)$ & 0.23 \\
\hline \multicolumn{7}{|l|}{ Residential area } \\
\hline Urban & $52.4(48.5,56.4)$ & $60.0(58.5,61.5)$ & $<0.001$ & $37.7(33.9,41.6)$ & $43.1(41.5,44.5)$ & 0.01 \\
\hline Rural & $56.9(51.4,62.5)$ & $57.7(55.4,60.1)$ & 0.80 & $42.6(37.1,48.4)$ & $42.2(39.9,44.5)$ & 0.90 \\
\hline \multicolumn{7}{|l|}{ Health insurance } \\
\hline $\mathrm{NHI}$ & $54.6(51.3,58.1)$ & $60.1(58.8,61.4)$ & 0.004 & $39.6(36.2,43.1)$ & $43.1(41.9,44.5)$ & 0.05 \\
\hline MAP & $40.0(29.2,51.9)$ & $48.2(41.9,54.7)$ & 0.22 & $30.1(19.9,42.6)$ & $37.8(31.7,44.3)$ & 0.26 \\
\hline
\end{tabular}

$\mathrm{Cl}$, confidence interval; $\mathrm{NHI}$, National Health Insurance; MAP, Medical Aid program.

rates for breast and cervical cancer (OR, 0.7; 95\% CI, 0.6 to 0.9 and OR, 0.7; 95\% CI, 0.5 to 0.9 ).

\section{DISCUSSION}

To the best of the authors' knowledge, this is one of the first studies conducted to evaluate and compare cancer screening rates between a group at high risk for cancer (people with diabetes) and non-high-risk group (non-diabetic participants) in the Korean population. Since the prevalence of diabetes in Korea continues to rapidly increase [14], receiving the appropriate screening for various cancers is important for people with diabetes. However, in this study using nationwide survey and health examination data, the cancer screening rate-including both the lifetime screening rate and the recommended screening rate for gastric, breast, and cervical cancers-were lower in people with diabetes than in people without diabetes, even though in Korea the government provides a NCSP in which screening examinations are provided free or at $10 \%$ of their normal charge to reduce the economic burden related to cancer screening.

Previous studies conducted in Western countries have consistently shown lower cancer screening rates in people with diabetes
$[9,10,16,17]$, similarly to our study. However, in a more recent study using nationwide surveillance data in the US, women with diabetes showed various screening behaviors compared with those without diabetes, including an equal rate of breast cancer screening, a lower rate of cervical cancer screening, and a higher rate of colorectal cancer screening [8]. However, these studies all targeted women. In this study, for gastric cancer screening, the target population for which includes both men and women, the screening rate in men was not different between the 2 groups, but women with diabetes showed a lower screening rate than women without diabetes, suggesting that women with diabetes were a more vulnerable population regarding the use of screening services, as shown in previous studies $[9,10,16,17]$. In Korea, invitation letters are sent to the eligible population for each type of cancer screening, and even though people with diabetes generally have more occasions to visit clinics for measurements of glucose levels or obtaining medication, their screening rate was lower. Previous studies have suggested that clinicians may focus on the clinical management of diabetes and its direct complications, while considering the prevention of long-term sequelae to be less important $[9,16,17]$. However, in Korea, the screening rates for diabetic retinopathy and nephropathy, which are direct complications of diabetes, were 
Table 3. Breast cancer screening rate in diabetic and non-diabetic participants (ever screened and recommended screening)

\begin{tabular}{|c|c|c|c|c|c|c|}
\hline & \multicolumn{3}{|c|}{ Ever screened } & \multicolumn{3}{|c|}{ Recommended screening } \\
\hline & Diabetes $(95 \% \mathrm{Cl})$ & No diabetes $(95 \% \mathrm{Cl})$ & $p$-value & Diabetes $(95 \% \mathrm{Cl})$ & No diabetes $(95 \% \mathrm{Cl})$ & $\mathrm{p}$-value \\
\hline Total & $60.5(57.7,64.8)$ & $71.5(69.9,73.1)$ & $<0.001$ & $38.8(34.5,43.3)$ & $44.6(42.9,46.5)$ & $<0.001$ \\
\hline \multicolumn{7}{|l|}{ Age (yr) } \\
\hline $40-49$ & $69.1(55.4,80.1)$ & $72.7(70.1,75.3)$ & 0.56 & $54.3(40.8,67.1)$ & $52.9(50.1,55.8)$ & 0.85 \\
\hline $50-59$ & $73.1(63.3,81.1)$ & $83.6(81.1,85.8)$ & 0.01 & $51.6(41.6,61.4)$ & $59.8(56.6,62.9)$ & 0.12 \\
\hline $60-69$ & $67.9(60.3,74.5)$ & $72.8(69.4,76.2)$ & 0.20 & $38.8(32.1,46.1)$ & $48.7(45.1,52.4)$ & 0.02 \\
\hline $70+$ & $39.6(32.7,46.9)$ & $43.2(39.4,47.4)$ & 0.40 & $20.1(15.4,25.8)$ & $27.9(24.8,31.4)$ & 0.02 \\
\hline \multicolumn{7}{|l|}{ Income } \\
\hline Lowest & $52.7(45.7,59.6)$ & $62.5(59.3,65.7)$ & 0.01 & $30.4(24.5,36.7)$ & $43.7(40.5,47.1)$ & $<0.001$ \\
\hline Lower & $62.2(53.6,70.2)$ & $68.5(65.2,71.7)$ & 0.15 & $41.9(33.5,50.7)$ & $46.1(42.6,49.5)$ & 0.39 \\
\hline Higher & $65.2(53.1,75.6)$ & $72.9(69.5,76.2)$ & 0.18 & $41.7(30.6,53.7)$ & $50.9(47.4,54.4)$ & 0.14 \\
\hline Highest & $76.5(65.4,84.8)$ & $81.9(79.1,84.4)$ & 0.25 & $49.4(38.2,60.7)$ & $60.9(57.4,64.3)$ & 0.05 \\
\hline \multicolumn{7}{|l|}{ Education } \\
\hline Elementary school & $56.5(51.1,61.8)$ & $63.8(61.4,66.2)$ & 0.01 & $35.1(30.1,40.4)$ & $43.8(41.4,46.3)$ & 0.003 \\
\hline Middle school & $68.5(54.7,79.6)$ & $74.9(70.7,78.7)$ & 0.31 & $44.9(31.6,58.9)$ & $51.1(46.7,55.5)$ & 0.41 \\
\hline High school & $70.3(57.4,80.5)$ & $75.5(72.6,78.2)$ & 0.37 & $42.6(31.7,54.2)$ & $54.8(51.5,58.1)$ & 0.05 \\
\hline College or more & $78.1(52.1,92.1)$ & $82.5(78.4,86.1)$ & 0.64 & $74.1(49.4,89.4)$ & $61.5(56.5,66.1)$ & 0.27 \\
\hline \multicolumn{7}{|l|}{ Residential } \\
\hline Urban & $59.8(54.3,65.1)$ & $72.2(70.3,74.1)$ & $<0.001$ & $37.3(32.2,42.7)$ & $50.7(48.7,52.7)$ & $<0.001$ \\
\hline Rural & $62.8(55.1,70.1)$ & $69.2(66.4,71.9)$ & 0.11 & $41.7(34.5,49.4)$ & $49.8(46.8,52.7)$ & 0.05 \\
\hline \multicolumn{7}{|l|}{ Medical insurance } \\
\hline $\mathrm{NHI}$ & $61.8(57.1,66.5)$ & $72.4(70.8,73.9)$ & $<0.001$ & $39.1(34.5,43.9)$ & $51.4(49.6,53.1)$ & $<0.001$ \\
\hline MAP & $47.4(34.1,61.1)$ & $56.6(49.1,63.8)$ & 0.26 & $32.8(21.4,46.7)$ & $36.6(29.7,44.1)$ & 0.63 \\
\hline
\end{tabular}

$\mathrm{Cl}$, confidence interval; NHI, National Health Insurance; MAP, Medical Aid program.

also found to be lower [18]. Previous studies have confirmed that this may be due to increased time constraints during screening periods, as many patients wish to receive screening examinations $[9,10,19]$. Additionally, some studies have proven that physicians who need to see many patients at a time are likely to neglect preventive care in patients with chronic diseases such diabetes, and prefer to focus on complicated cases [20,21]. In addition, this pattern might be caused by a trend for clinical practice in Korea to be focused on treatment rather than prevention. Considering the increasing prevalence of diabetes and the decreasing mortality due to diabetes, long-term management of diabetes using appropriate preventive health care strategies, including cancer screening and addressing other long-term sequelae, should be considered important.

Lower cancer screening rates in older people with diabetes than in people without diabetes in the same age group, especially regarding the recommended screenings for gastric and breast cancer, were observed. A study conducted in the US [22] reported similar results, and suggested that this may have been because subjects did not believe that screenings conferred survival benefits. Diabetic people with the lowest education level received less screening than their non-diabetic counterparts. The results of this study agree with other study findings proposing that lower economic and educational levels are correlated with low compliance with screening recommendations, which suggests that sociocul- tural barriers and adequate health education may be responsible for the lower screening rate in this subgroup [8,19,23-25]. In this study, the cancer screening rate increased with income and educational level in both groups (people with and without diabetes), but in diabetic individuals, the increment was more prominent for education level than for income. Therefore, to increase the cancer screening rate in people with diabetes, efforts should be focused on less-educated people with diabetes. This is consistent with previous studies showing that higher education was a positive predictor for both tests among diabetic women [10]. Urbanity also was not left out in this study, and we observed a lower screening rate among diabetic individuals living in urban areas than among their non-diabetic urban counterparts. It is challenging to see how this may reflect real-life circumstances, as participants living in urban areas have greater opportunities to receive screenings than their rural counterparts and are aware of the benefits of screening. After adjusting for other socioeconomic factors, diabetic participants still showed lower lifetime screening and recommended screening rates for all 3 cancers than those without diabetes.

Although this study has several limitations, such as the inclusion of self-reported data without matching medical records, we believe that the bias was minimal and that the results are representative of the Korean population. We did not take into consideration the characteristics of diabetes (type and duration), which 
Table 4. Cervical cancer screening rate in diabetic and non-diabetic participants (ever screened and recommended screening)

\begin{tabular}{|c|c|c|c|c|c|c|}
\hline & \multicolumn{3}{|c|}{ Ever screened } & \multicolumn{3}{|c|}{ Recommended screening } \\
\hline & Diabetes $(95 \% \mathrm{Cl})$ & No diabetes $(95 \% \mathrm{Cl})$ & $p$-value & Diabetes $(95 \% \mathrm{Cl})$ & No diabetes $(95 \% \mathrm{Cl})$ & $\mathrm{p}$-value \\
\hline Total & $49.1(44.7,53.5)$ & $59.6(58.2,61.0)$ & $<0.001$ & $35.1(31.0,39.4)$ & $51.2(49.7,52.6)$ & $<0.001$ \\
\hline \multicolumn{7}{|l|}{ Age (yr) } \\
\hline $30-39$ & $54.1(36.6,70.4)$ & $57.1(54.4,59.8)$ & 0.73 & $27.7(15.2,44.8)$ & $51.2(48.3,53.8)$ & 0.007 \\
\hline $40-49$ & $48.2(35.1,61.6)$ & $64.9(62.2,67.5)$ & 0.01 & $56.9(43.5,69.3)$ & $62.2(59.4,65.0)$ & 0.43 \\
\hline $50-59$ & $57.3(47.3,66.6)$ & $68.3(65.4,71.1)$ & 0.03 & $47.1(37.3,69.3)$ & $58.0(54.8,61.1)$ & 0.04 \\
\hline $60-69$ & $55.2(47.5,62.2)$ & $60.3(56.6,63.8)$ & 0.23 & $33.8(27.3,41.1)$ & $41.3(37.8,44.9)$ & 0.07 \\
\hline $70+$ & $36.9(30.1,44.3)$ & $34.7(31.2,38.4)$ & 0.58 & $18.2(13.6,24.0)$ & $20.1(17.2,23.3)$ & 0.55 \\
\hline \multicolumn{7}{|l|}{ Income } \\
\hline Lowest & $40.6(34.1,47.5)$ & $49.8(46.6,52.9)$ & 0.02 & $22.3(17.5,27.5)$ & $37.3(34.3,40.4)$ & $<0.001$ \\
\hline Lower & $56.3(48.1,64.2)$ & $58.9(56.1,61.7)$ & 0.55 & $41.5(33.4,50.1)$ & $47.8(44.9,50.8)$ & 0.17 \\
\hline Higher & $56.4(45.2,67.1)$ & $61.4(58.7,64.0)$ & 0.39 & $42.4(31.6,54.0)$ & $52.3(49.5,55.0)$ & 0.10 \\
\hline Highest & $51.3(40.5,62.1)$ & $65.1(62.6,67.6)$ & 0.01 & $44.9(34.5,55.8)$ & $62.7(59.9,65.4)$ & 0.001 \\
\hline \multicolumn{7}{|l|}{ Education } \\
\hline Elementary school & $46.9(41.5,52.4)$ & $53.8(51.4,56.3)$ & 0.02 & $32.2(27.3,37.7)$ & $37.8(35.4,40.7)$ & 0.06 \\
\hline Middle school & $58.5(45.2,70.2)$ & $64.2(60.3,67.9)$ & 0.40 & $38.6(26.6,52.3)$ & $53.1(48.8,57.3)$ & 0.04 \\
\hline High school & $51.2(40.8,61.5)$ & $61.3(59.1,63.7)$ & 0.06 & $39.5(29.9,49.9)$ & $56.6(54.1,59.1)$ & 0.001 \\
\hline College or more & $55.8(37.0,73.1)$ & $61.9(58.9,64.8)$ & 0.52 & $54.2(35.7,71.7)$ & $59.1(55.9,62.1)$ & 0.62 \\
\hline \multicolumn{7}{|l|}{ Residential } \\
\hline Urban & $49.8(44.6,55.0)$ & $60.2(58.8,61.6)$ & $<0.001$ & $35.5(30.7,40.7)$ & $53.2(51.5,54.8)$ & $<0.001$ \\
\hline Rural & $46.7(39.2,54.2)$ & $47.7(40.6,54.9)$ & 0.04 & $35.5(30.7,40.7)$ & $53.2(51.5,54.8)$ & $<0.001$ \\
\hline \multicolumn{7}{|l|}{ Medical Insurance } \\
\hline $\mathrm{NHI}$ & $49.3(44.1,54.1)$ & $81.2(80.1,82.5)$ & $<0.001$ & $35.5(31.2,40.1)$ & $52.2(50.7,53.6)$ & $<0.001$ \\
\hline MAP & $52.4(38.8,65.6)$ & $60.1(52.4,67.3)$ & 0.56 & $33.1(26.3,38.1)$ & $31.6(24.4,38.6)$ & 0.83 \\
\hline
\end{tabular}

$\mathrm{Cl}$, confidence interval; NHI, National Health Insurance; MAP, Medical Aid program.

Table 5. Multivariate logistic regression' in diabetic and non-diabetic participants

\begin{tabular}{|c|c|c|c|c|c|}
\hline & & \multicolumn{2}{|c|}{ Ever screened } & \multicolumn{2}{|c|}{ Recommended screening } \\
\hline & & OR $(95 \% \mathrm{Cl})$ & $p$-value & OR $(95 \% \mathrm{Cl})$ & $\mathrm{p}$-value \\
\hline \multirow[t]{2}{*}{ Gastric cancer } & No & 1.0 (reference) & & 1.0 (reference) & \\
\hline & Yes & $0.8(0.7,0.9)$ & 0.02 & $0.9(0.7,1.0)$ & 0.19 \\
\hline \multirow[t]{2}{*}{ Breast cancer } & No & 1.0 (reference) & & 1.0 (reference) & \\
\hline & Yes & $0.8(0.6,1.0)$ & 0.06 & $0.7(0.6,0.9)$ & 0.02 \\
\hline \multirow[t]{2}{*}{ Cervical cancer } & No & 1.0 (reference) & & 1.0 (reference) & \\
\hline & Yes & $0.7(0.6,0.9)$ & 0.01 & $0.7(0.5,0.9)$ & 0.004 \\
\hline
\end{tabular}

$\mathrm{OR}$, odds ratio; $\mathrm{Cl}$, confidence interval.

${ }^{1}$ Adjusted for age, gender, income level, education, residential area, and medical insurance.

may influence compliance with screening guidelines, and we likewise did not have information that could help measure the efficacy of diabetes care management programs. In addition, we were not able to estimate colorectal and liver cancer screening rates, even though they are included in the NCSP. Both of these cancers have more than one screening method. For liver cancer screening, an alpha-fetoprotein test and sonography are recommended, and for colorectal cancer, a yearly fecal occult blood test in combination with colonoscopy or a double-contrast enema in the case of abnormal findings is recommended. We considered liver cancer screening, which targets high-risk populations such as hepatitis B or C carriers and individuals with liver cirrhosis, but it was not considered appropriate to make a comparison between people with and without diabetes in those populations. In addition, for colorectal cancer screening, the options in the questionnaire regarding the screening interval included less than 2, 2-5, 5-10, and 10 years or more, in contrast to the NCSP guidelines. This ambiguity, and the limited choices on the questionnaire, led us not to analyze colorectal cancer in this study. However, screening for liver and colorectal cancer will be a point of concern for future research.

In conclusion, this study showed a lower screening rate in peo- 
ple with diabetes, and we propose that in the future, continuous public health efforts should emphasize the importance of longterm preventive care, including cancer screening, for high-risk populations such as individuals with diabetes. We further suggest that future research should focus on the cancer screening rate by type and duration of diabetes and the medication used.

\section{CONFLICT OF INTEREST}

The authors have no conflicts of interest to declare for this study.

\section{ORCHID}

Kumban Walter Chuck: http://orcid.org/0000-0001-5701-9173; Minji Hwang: http://orcid.org/0000-0003-4637-115X; Kui Son Choi: http://orcid.org/0000-0001-5336-3874; Mina Suh: http://orcid.org/ 0000-0001-8101-7493; Jae Kwan Jun: http://orcid.org/0000-00031647-0675; Boyoung Park: http://orcid.org/0000-0003-1902-3184

\section{REFERENCES}

1. Torre LA, Bray F, Siegel RL, Ferlay J, Lortet-Tieulent J, Jemal A. Global cancer statistics, 2012. CA Cancer J Clin 2015;65:87-108.

2. World Health Organization. Global report on diabetes; 2016 [cited 2017 Oct 17]. Available from: http://apps.who.int/iris/bitstream/ 10665/204871/1/9789241565257_eng.pdf.

3. Giovannucci E, Harlan DM, Archer MC, Bergenstal RM, Gapstur SM, Habel LA, et al. Diabetes and cancer: a consensus report. CA Cancer J Clin 2010;60:207-221.

4. Tseng CH, Tseng FH. Diabetes and gastric cancer: the potential links. World J Gastroenterol 2014;20:1701-1711.

5. Hardefeldt PJ, Edirimanne S, Eslick GD. Diabetes increases the risk of breast cancer: a meta-analysis. Endocr Relat Cancer 2012; 19:793-803.

6. Kuriki K, Hirose K, Tajima K. Diabetes and cancer risk for all and specific sites among Japanese men and women. Eur J Cancer Prev 2007;16:83-89.

7. Iqbal N. The burden of type 2 diabetes: strategies to prevent or delay onset. Vasc Health Risk Manag 2007;3:511-520.

8. Zhao G, Ford ES, Ahluwalia IB, Li C, Mokdad AH. Prevalence and trends of receipt of cancer screenings among US women with diagnosed diabetes. J Gen Intern Med 2009;24:270-275.

9. Lipscombe LL, Hux JE, Booth GL. Reduced screening mammography among women with diabetes. Arch Intern Med 2005;165: 2090-2095.

10. Jiménez-Garcia R, Hernandez-Barrera V, Carrasco-Garrido P, Gil A. Prevalence and predictors of breast and cervical cancer screening among Spanish women with diabetes. Diabetes Care
2009;32:1470-1472.

11. Lim D, Ha M, Song I. Trends in major cancer mortality in Korea, 1983-2012, with a joinpoint analysis. Cancer Epidemiol 2015;39: 939-946.

12. Oh CM, Won YJ, Jung KW, Kong HJ, Cho H, Lee JK, et al. Cancer statistics in Korea: incidence, mortality, survival, and prevalence in 2013. Cancer Res Treat 2016;48:436-450.

13. Suh M, Choi KS, Park B, Lee YY, Jun JK, Lee DH, et al. Trends in cancer screening rates among Korean men and women: results of the Korean National Cancer Screening Survey, 2004-2013. Cancer Res Treat 2016;48:1-10.

14. Kim DJ. The epidemiology of diabetes in Korea. Diabetes Metab J 2011;35:303-308.

15. Shin HY, Lee JY, Song J, Lee S, Lee J, Lim B, et al. Cause-of-death statistics in the Republic of Korea, 2014. J Korean Med Assoc 2016; 59:221-232.

16. McBean AM, Yu X. The underuse of screening services among elderly women with diabetes. Diabetes Care 2007;30:1466-1472.

17. Martinez-Huedo MA, Lopez de Andres A, Hernandez-Barrera V, Carrasco-Garrido P, Martinez Hernandez D, Jiménez-Garcia R. Adherence to breast and cervical cancer screening in Spanish women with diabetes: associated factors and trend between 2006 and 2010. Diabetes Metab 2012;38:142-148.

18. Byun SH, Ma SH, Jun JK, Jung KW, Park B. Screening for diabetic retinopathy and nephropathy in patients with diabetes: a nationwide survey in Korea. PLoS One 2013;8:e62991.

19. Owens MD, Beckles GL, Ho KK, Gorrell P, Brady J, Kaftarian JS. Women with diagnosed diabetes across the life stages: underuse of recommended preventive care services. J Womens Health (Larchmt) 2008;17:1415-1423.

20. Streja DA, Rabkin SW. Factors associated with implementation of preventive care measures in patients with diabetes mellitus. Arch Intern Med 1999;159:294-302.

21. Beckman TJ, Cuddihy RM, Scheitel SM, Naessens JM, Killian JM, Pankratz VS. Screening mammogram utilization in women with diabetes. Diabetes Care 2001;24:2049-2053.

22. Bynum JP, Braunstein JB, Sharkey P, Haddad K, Wu AW. The influence of health status, age, and race on screening mammography in elderly women. Arch Intern Med 2005;165:2083-2088.

23. Luengo-Matos S, Polo-Santos M, Saz-Parkinson Z. Mammography use and factors associated with its use after the introduction of breast cancer screening programmes in Spain. Eur J Cancer Prev 2006;15:242-248.

24. Larizgoitia I, Starfield B. Reform of primary health care: the case of Spain. Health Policy 1997;41:121-137.

25. Coughlin SS, Uhler RJ, Hall HI, Briss PA. Nonadherence to breast and cervical cancer screening: what are the linkages to chronic disease risk. Prev Chronic Dis 2004;1:A04. 
Appendix 1. Cancer screening protocol issued by the national screening program in Korea

\begin{tabular}{|c|c|c|c|}
\hline Cancer type & Target population & Screening method & Interval (yr) \\
\hline Stomach cancer & $\begin{array}{l}\geq 40 \mathrm{yr} \text { old } \\
\text { Men and women }\end{array}$ & Gastric endoscopy or upper gastro-intestinal series & Every 2 \\
\hline Colorectal cancer & $\begin{array}{l}\geq 50 \text { yr old } \\
\text { Men and women }\end{array}$ & Fecal occult blood test and if positive, colonoscopy or barium Enema & Every \\
\hline Breast cancer & $\begin{array}{l}\geq 40 \text { yr old } \\
\text { Women }\end{array}$ & Mammography & Every 2 \\
\hline Cervical cancer & $\begin{array}{l}\geq 30 \mathrm{yr} \text { old } \\
\text { Women }\end{array}$ & Pap smear & Every 2 \\
\hline
\end{tabular}

